\title{
Effects of gamma radiation on the elastic properties of thulium doped zinc borotellurite glass
}

\begin{abstract}
Effects of gamma radiation on the elastic properties of $\{[(\mathrm{TeO} 2) 0.7(\mathrm{~B} 2 \mathrm{O} 3) 0.3] 0.7[\mathrm{ZnO}]$ $0.3\} 0.99\{\mathrm{Tm} 2 \mathrm{O} 3\} 0.01$ (thulium doped zinc borotellurite glass) were investigated. Glass samples were prepared using the melt-quenching technique. Density and ultrasonic velocity of glasses before and after irradiation process were measured using Electronic Densimeter MD-300S and Ritec Ram-5000 Snap System, respectively. Next, elastic moduli and Poisson's ratio of the glasses were calculated. Atomic ring size of the glass network was also calculated to support the attained results. Results show that density varied after radiation and maximised at $20 \mathrm{kGy}$. This is attributed to the breaking and rearrangement of chemical bonding in the glass network due to radiation. Furthermore, all elastic parameters exhibited an increasing trend that indicated the strengthening of the glass samples as well as increment of its rigidity. Besides that, atomic ring size was found to decrease as radiation dose increased. This indicate that compaction of glass network took place as the samples were exposed to gamma rays which in turn contributed to the elevation of elastic moduli of the prepared glass.
\end{abstract}

Keyword: Borotellurite glass; Density; Elastic; Gamma radiation; Poisson's ratio; Thulium 